\title{
Effective Biodegradation of Mycotoxin Patulin by Porcine Pancreatic Lipase
}

\author{
Bingjie Liu, Xiaoning Peng and Xianghong Meng* \\ College of Food Science and Engineering, Ocean University of China, Qingdao, China
}

Patulin is a common contaminant in fruits and vegetables, which is difficult to remove. In this study, the biodegradation of patulin using porcine pancreatic lipase (PPL) was investigated. The method of HPLC was used to analyze the concentration of patulin. Batch degradation experiments were performed to illustrate the effect of PPL amount, $\mathrm{pH}$, temperature, contact time, and initial concentration. Besides, the degradation product of patulin was characterized by full wavelength scanning and MS technologies. The results showed that the optimum degradation conditions of PPL for patulin was observed at $\mathrm{pH} 7.5,40^{\circ} \mathrm{C}$ for $48 \mathrm{~h}$. The percentage of degradation could reach above $90 \%$. The structure of degradable product of patulin was inferred by the molecular weight 159.0594, named $\mathrm{C}_{7} \mathrm{H}_{11} \mathrm{O}_{4}{ }^{+}$. It indicated that PPL was effective for the degradation of patulin in fruits and vegetables juice.

Keywords: porcine pancreatic lipase, patulin, biodegradation, characterization, molecular structure

OPEN ACCESS

Edited by:

Nengguo Tao,

Xiangtan University, China

Reviewed by:

Jun Tian,

Jiangsu Normal University, China Xingfeng Shao, Ningbo University, China

*Correspondence: Xianghong Meng mengxh@ouc.edu.cn

Specialty section: This article was submitted to

Food Microbiology, a section of the journal

Frontiers in Microbiology

Received: 01 November 2017 Accepted: 16 March 2018 Published: 09 April 2018

Citation:

Liu B, Peng $X$ and Meng X (2018) Effective Biodegradation of Mycotoxin Patulin by Porcine Pancreatic Lipase.

Front. Microbiol. 9:615.

doi: 10.3389/fmicb.2018.00615

\section{INTRODUCTION}

Patulin (4-hydroxy-4H-furo [3, 2c] pyran-2 [6H]-one), a mycotoxin contamination, is synthesized by various fungi, particularly Penicillium, Aspergillus, and Byssochlamys species (Moake et al., 2005; Castoria et al., 2011; Zhu et al., 2015) (Figure 1). These fungi are important post-harvest pathogens of apples, pears, peaches, apricots as well as some vegetables (e.g., tomatoes) and caused the accumulation of patulin in infected products (Yuan et al., 2010; Castoria et al., 2011). Patulin poses a health risk to humans and livestock following acute and chronic effects, even at relatively low concentration (Moake et al., 2005; Zhu et al., 2015; Peng et al., 2016). Due to its toxicity, many countries and organizations, including China and WHO, have established the provisional maximum permitted level of patulin contamination for fruit- and vegetable-derived products (Food Agricultural Organization/World Health Organization [FAO/WHO], 1995; Castoria et al., 2005; Yuan et al., 2010). Therefore, it's necessary to remove patulin from foodstuffs.

The commonly used strategies for patulin removal include filtering and adsorption, electromagnetic irradiation, chemical addition, and biological degradation (Moake et al., 2005; Li et al., 2015). However, some problems still exist in the use of available physical and chemical methods for patulin detoxification, such as safety issues, possible losses in the nutritional quality, environmental damages, limited efficacy, and high cost (Kabak et al., 2006; Guo et al., 2013; Dong et al., 2015). So, the use of biological agents as an alternative strategy is considered as a powerful potential method (Dong et al., 2015). Besides, patulin was nearly degraded completely during the yeast Saccharomyces cerevisiae fermentation, this method was more useful than the other decontamination ones (Moake et al., 2005). It has been reported that the biocontrol Yeast Rhodosporidium kratochvilovae strain LS11 can reduce patulin contamination in the stored fruit (Castoria et al., 2011) and the complete degradation of patulin was observed within 48 and $72 \mathrm{~h}$ in the presence of $15 \mu \mathrm{g} / \mathrm{mL}$ patulin (Reddy et al., 2011). A later study showed that a strain of marine 


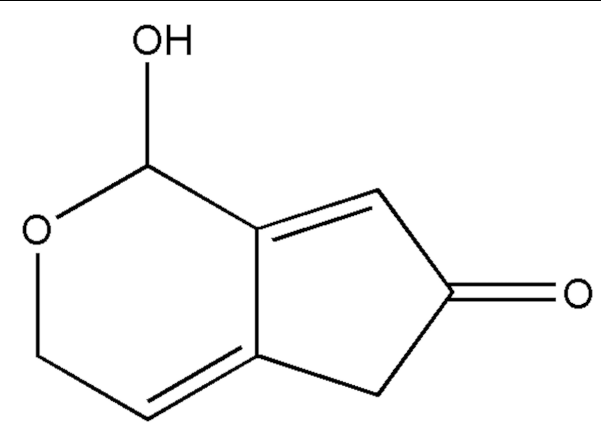

FIGURE 1 | Molecular structure of patulin.

yeast renamed K. ohmeri HYJM34 was screened, which has high patulin degradation ability, and the biodegradation of patulin by $K$. ohmeri might be an enzymatically driven process (Dong et al., 2015). However, biological control with yeast is limited to product that it could be fermented in the process (Moake et al., 2005).

The structure of patulin reveals the presence of a lactone bond. Therefore, reducing enzymes such as those involved in yeast fermentation, as well as lactone degrading enzymes such as lactamase, may well be able to degrade patulin alone (Moake et al., 2005). This paper was focus on investigating the effect of enzymes for patulin degradation.

Lipases (triacylglycerol ester hydrolases; E.C. 3.1.1.3) are found in microorganisms, plants and animal tissues. Among them, porcine pancreatic lipase (PPL) is one of the most widely used lipases in catalyzing a variety of reactions, such as esterification, interesterification and hydrolysis, which is cheaper than other commercial microbial and animal lipases (Kartal et al., 2009; Li et al., 2009; Mendes et al., 2012). The PPL investigated is composed of a single chain of 449 kinds of amino acids and 7 kinds of disulfide bonds (Giessauf and Gamse, 2000; Mendes et al., 2012). PPL had already been used as a biocatalyst for enantioselective esterification of glycidol (Martins et al., 1994) and enzymatic hydrolysis of triolein as well as its partial glycerides (Glowacz et al., 1996). In this study, PPL was chosen as a catalyzer that could be possibly used for patulin degradation.

So far, there are few studies about the direct enzymatic degradation of patulin. The aim of this work was to study the degradation of patulin using PPL, which can provide a kind of material to degrade patulin in fruits and vegetables product. And the purpose of this study reported here were to investigate the degradation rate of PPL for patulin at various conditions and characterize the action mechanism by full wavelength scanning and mass spectrometry analysis.

\section{MATERIALS AND METHODS}

\section{Materials}

The PPL (type II, E.C. 3.1.1.3, with a specific activity of 100-400 olive oil units per milligram of protein) was supplied by Sigma-Aldrich, Co., Ltd. (St. Louis, MO, United States); acetic acid was of analytical purity and used as received without further purification. Acetonitrile and chloroform were of high performance liquid chromatography grade. Patulin was obtained from Sigma-Aldrich, Co., Ltd. Ultrapure water was used throughout all of the experiments.

\section{Preparation of Patulin Solution Working Solution A}

Solid patulin was dissolved into $50 \mathrm{~mL}$ of chloroform to obtain $100 \mathrm{mg} / \mathrm{L}$ standard patulin solution, and stored at $-18^{\circ} \mathrm{C}$. The patulin standard solution could evaporated to dry, then dissolved in deionized water (adjusted to $\mathrm{pH} 4.0$ with acetic acid) with the final concentration of $5 \mathrm{mg} / \mathrm{L}$ (Zhang et al., 2016). The working solution A was obtained.

\section{Working Solution B}

The Penicillium expansum strain M1 was obtained by our laboratory. Strains M1 was cultivated at $28^{\circ} \mathrm{C}$ for 14 days in PDA medium. The patulin extraction process was prepared according to the methodology described by MacDonald et al. (2000) with some modifications: the mixture of fungus and culture medium was separated, followed by extracting three times with ethyl acetate, cleaned up by extraction with $10 \mathrm{~mL}$ of a $1.5 \%(\mathrm{w} / \mathrm{v})$ sodium bicarbonate aqueous solution. The ethyl acetate extract was passed over a shaker-incubator with $180 \mathrm{r} / \mathrm{min}, 25^{\circ} \mathrm{C}$ for $1 \mathrm{~h}$ and evaporated to dryness. Then, patulin was dissolved into $1 \mathrm{~mL}$ deionized water, adjusted to $\mathrm{pH} 4.0$ with acetic acid. Thus, the working solution B was obtained.

\section{Patulin Degradation by PPL}

The degradation experiments of patulin in aqueous solution were carried out in $50 \mathrm{~mL}$ Erlenmeyer flasks. The powdered PPL was added to $5 \mathrm{~mL}$ working solution B constantly. The control was prepared without addition of PPL (Guo et al., 2013). They were placed on a shaker-incubator with $180 \mathrm{r} / \mathrm{min}$, $30^{\circ} \mathrm{C}$. The concentration of patulin in aqueous solution after the degradation could be measured by HPLC. Then, $0.45 \mu \mathrm{m}$ microPES (Shimadzu, Japan) was used for purification before detection (Peng et al., 2016). The samples were detected by HPLC with UV detection (Li et al., 2007).

The effect of lipase amounts on degradation rate was investigated in the range of $0.3-2.4 \mathrm{mg}$. The effect of $\mathrm{pH}$ was investigated at the $\mathrm{pH}$ range from 3.5 to 8.5 . The $\mathrm{pH}$ value was adjusted to the desired $1 \mathrm{~mol} / \mathrm{L}$ phosphate buffer solution. The effect of temperature on degradation rate was investigated ranging from 20 to $60^{\circ} \mathrm{C}$. The effect of contact time was conducted at nine different levels every $6 \mathrm{~h}$ for $54 \mathrm{~h}$. The effect of initial patulin concentration was conducted in the range of 5-30 mg/L.

The degradation rate of PPL for patulin was calculated using Eq. (1):

$$
\omega=\frac{C_{0}-C_{\mathrm{e}}}{C_{0}}
$$

where, $\omega(\%)$ is the degradation rate of PPL for patulin; $C_{0}$ and $C_{\mathrm{e}}$ $(\mathrm{mg} / \mathrm{L})$ are the initial and equilibrium concentrations of patulin in the solutions, respectively. 
The degradation capacity of PPL for patulin was calculated using Eq. (2).

$$
q_{\mathrm{e}}=\frac{\left(C_{0}-\mathrm{C}_{\mathrm{e}}\right) \times V}{m}
$$

where, $q_{\mathrm{e}}(\mathrm{mg} / \mathrm{mg})$ is the degradation capacity of PPL for patulin; $C_{0}$ and $C_{\mathrm{e}}(\mathrm{mg} / \mathrm{L})$ are the initial and equilibrium concentrations of patulin in the solutions, respectively. $V(\mathrm{~mL})$ is the volume of patulin aqueous solutions and $m(\mathrm{mg})$ is the mass of dry PPL.

\section{Ultrafiltration and Determination}

The Vivaspin centrifugal concentrators with a molecular weight cut off of 3000 were obtained from Millipore (Bedford, MA, United States). The samples were transferred to Vivaspin centrifugal filters spun at $4000 \times g$ in swing bucket rotor at $25^{\circ} \mathrm{C}$ for $10 \mathrm{~min}$ to deplete the high molecular weight proteins. Finally, $1 \mathrm{~mL}$ of patulin degradation was collected (Zheng et al., 2006).

Then, a 1260 HPLC system (Agilent, United States) equipped with UV detector was used to detect the concentration of patulin. The analytical column was Agilent ZORBAX SB-C18, $5 \mu \mathrm{m} \times 4.6 \mathrm{~mm} \times 250 \mathrm{~mm}$; no guard column was used. The mobile phase, eluting at a flow rate of $1 \mathrm{~mL} / \mathrm{min}$, consisted of an isocratic mixture of acetonitrile/water (1:9, v:v). The chromatograms for calculations were extracted at $276 \mathrm{~nm}$. The HPLC column was conditioned before analysis by running a background without injection. For regular analysis, $20 \mu \mathrm{L}$ of sample or standard solution was injected. In addition to samples and calibration standards, control samples were analyzed for each matrix. The requirements for recovery of these samples were set to $60-115 \%$. The limits of detection and quantification were 10.78 and $32.67 \mu \mathrm{g} / \mathrm{L}$, respectively (Li et al., 2015).

\section{Identification of the Degradation Products}

The powdered PPL was added to $5 \mathrm{~mL}$ working solution A constantly.

The optical spectra of samples were recorded by using a Unico UV2102-PC UV-Visible spectrophotometer (Shanghai, China) (Zhu et al., 2016). The samples at $24 \mathrm{~h}$ were transferred to Vivaspin centrifugal filters spun at $4000 \times g$ for $10 \mathrm{~min}$ to deplete the PPL. Finally, $1 \mathrm{~mL}$ of patulin degradation product was collected. The preparation of patulin solutions was diluted by ultrapure water. And the UV-vis spectra were recorded from 190 to $700 \mathrm{~nm}$.

Accurate-Mass Q-TOF LC/MS (Agilent, United States) was used. The molecular weight of patulin degradation products was identified by was determined by ESI-MS. The mobile phase eluting at a flow rate of $0.4 \mathrm{~mL} / \mathrm{min}$, consisted of an isocratic mixture of methanol/water $(1: 9, \mathrm{v}: \mathrm{v})$. The sample injection volume was $20 \mu \mathrm{L}$. ESI-MS experiments were performed on positive ionization mode. The MS operation parameters were set as followed: capillary voltage $4000 \mathrm{~V}$, drying gas flow $10 \mathrm{~L} / \mathrm{min}$, drying gas temperature $350^{\circ} \mathrm{C}$, vaporizer temperature $450^{\circ} \mathrm{C}$, and nebulizer pressure $40 \mathrm{psi}$. The optimal fragmentor voltage was $50 \mathrm{~V}$, with a mass range of $\mathrm{m} / \mathrm{z} 20-500$ for MS/MS scan modes containing product and precursor ion scans. The Agilent Mass Hunter software package (version 6.1) was used for data acquisition and analysis (Agilent, United States).

\section{Statistical Analyses}

All of the experiments were carried out in triplicate, and the results were expressed as means \pm standard deviation. The data was analyzed by one-way analysis of variance (ANOVA) using SPSS (version 19.0, SPSS, Inc.), and Duncan's multiple comparisons were adopted to assess the statistical significance $(P<0.05)$.

\section{RESULTS AND DISCUSSION}

\section{Effect of PPL Amount on Degradation Rate and Degradation Capacity}

The dosage of PPL added into $5 \mathrm{~mL}$ patulin solution varied between 0.3 and $2.4 \mathrm{mg}$. Experiments were performed at $30^{\circ} \mathrm{C}$ for $30 \mathrm{~h}$. As can be seen from Figure 2, the degradation rate of patulin increased obviously with the increasing of PPL concentration in solution and approached equilibrium at $0.36 \mathrm{mg} / \mathrm{mL}$. It is more likely to predict that PPL catalyzed the degradation of patulin, while the substrate-binding sites maybe have reached to the saturation point as the concentration of PPL was above $0.36 \mathrm{mg} / \mathrm{mL}$. However, the degradation capacity of PPL was decreased drastically between 0.06 and $0.18 \mathrm{mg} / \mathrm{mL}$, later, it kept invariability. This is probably because that the velocity of PPL promoting reaction was related with the concentration of patulin. Thus, the optimal addition of PPL was $1.8 \mathrm{mg} / 5 \mathrm{~mL}$.

\section{Effect of pH on Degradation Rate and Degradation Capacity}

Experiments were performed at the controlled $\mathrm{pH}(3.5-8.5)$ and $30^{\circ} \mathrm{C}$ by shaking $1.8 \mathrm{mg}$ of PPL with $5 \mathrm{~mL}$ of patulin solutions

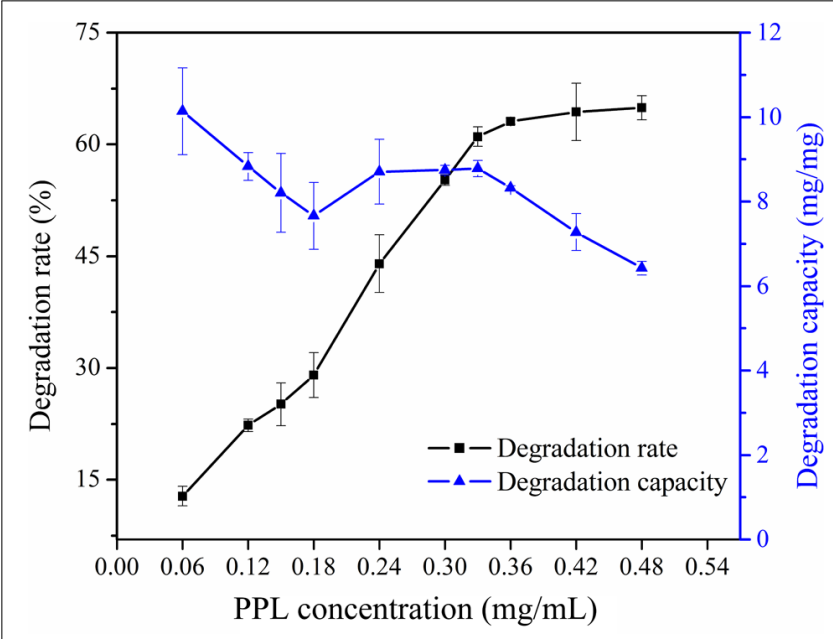

FIGURE 2 | Effect of enzyme concentration on degradation rate and degradation capacity of PPL for patulin. 
for $30 \mathrm{~h}$ with $180 \mathrm{r} / \mathrm{min}$. Results were shown in Figure 3. It indicated that the degradation rate was the highest at $\mathrm{pH}$ 7.5. The degradation rate changed insignificantly in the range of 3.5-5.5. This may be explained by the stability of patulin in acidic condition, and meanwhile, the activity of PPL was inhibited. As $\mathrm{pH}$ may not only affect the shape of an enzyme, but also it may change the shape or charge properties of the substrate. The data also demonstrated that the degradation rate increased between $\mathrm{pH} 5.5$ and 7.5, later, it changed slightly at high $\mathrm{pH}$. In general, the effect of $\mathrm{pH}$ probably results from the activity of enzyme. Therefore, the degradation capacity and degradation rate had the same change trend at early stage, which increased from $\mathrm{pH}$ 3.5 to 7.5 . However, the degradation capacity declined quickly at $\mathrm{pH}$ 8.5. This was because that the activity of PPL was still high, but the patulin content of controlled group was declined significantly for the instability of patulin. Therefore, $\mathrm{pH} 7.5$ was selected as the optimal $\mathrm{pH}$ in the following experiments.

\section{Effect of Temperature on Degradation Rate and Degradation Capacity}

The effect of temperature on degradation rate of PPL for patulin was studied at pH 7.5 and the results were shown in Figure 4. The degradation rate increased greatly with an increasing of temperature from 10 to $40^{\circ} \mathrm{C}$ and then onwards changes slightly. A possible explanation for the results was that the active site of an enzyme was the region that binds the substrates (Berg et al., 2002). The reaction rate would increase with the rising of temperature because the substrates would collide more frequently with PPL active site. And the heat of molecules in the system would increase. Thus, the degradation capacity increased as the temperature raised from 10 to $40^{\circ} \mathrm{C}$. The increase of degradation capacity of PPL for patulin with increasing of temperature indicated that the nature of PPL hydrolysis process for patulin was endothermic (Kannamba et al., 2010). Besides, the reaction capacity then abruptly declined with further increase

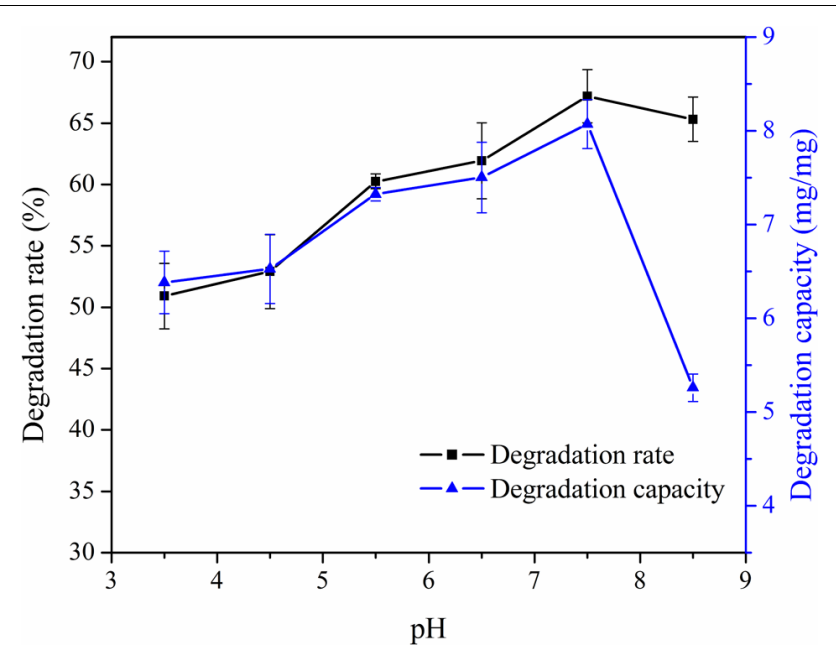

FIGURE 3 | Effect of $\mathrm{pH}$ on degradation rate and degradation capacity of PPL for patulin. of temperature. This is not only because PPL activity was low, but the patulin content of controlled group was also declined obviously at $60^{\circ} \mathrm{C}$. Hence, the optimal temperature was set at $40^{\circ} \mathrm{C}$ for further studies.

\section{Effect of Initial Patulin Concentration on Degradation Rate and Degradation Capacity}

Effect of initial concentration of patulin was investigated. Taken into consideration need of practical application, experiments were conducted containing $5-30 \mathrm{mg} / \mathrm{L}$ patulin at $40^{\circ} \mathrm{C}$ for $30 \mathrm{~h}$ with $180 \mathrm{r} / \mathrm{min}$ (Figure 5). The results showed that the degradation rate declined evidently first and then remained steady in varying initial concentration from 15 to $30 \mathrm{mg} / \mathrm{L}$. It was indicated that the degradation effect of patulin was favorable
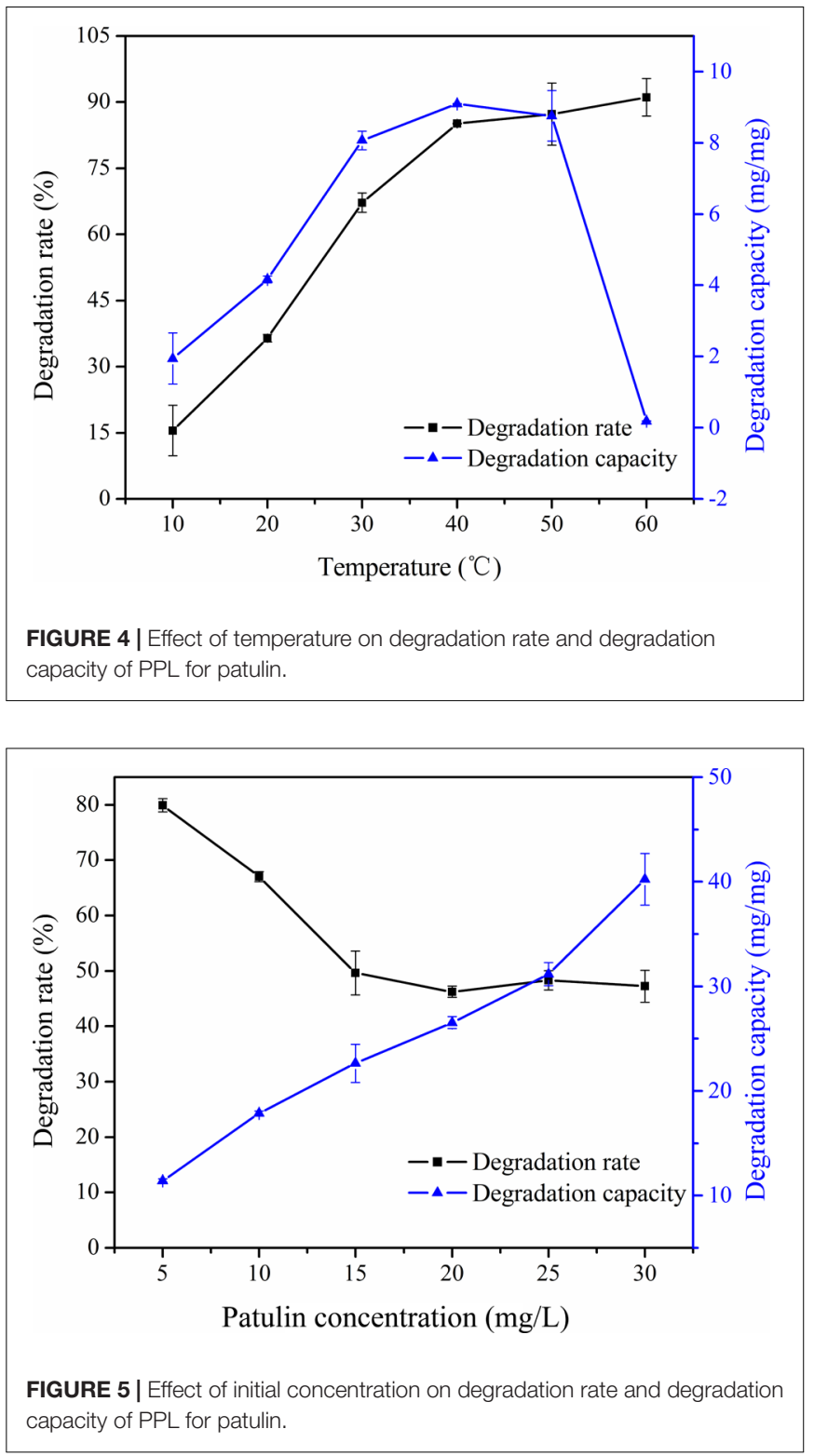


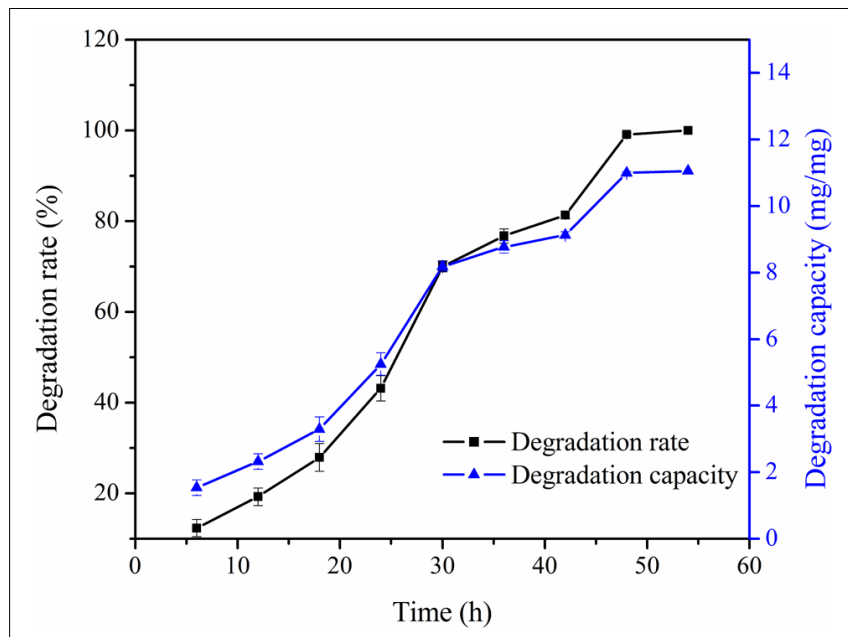

FIGURE 6 | Effect of contact time on degradation rate and degradation capacity of PPL for patulin.

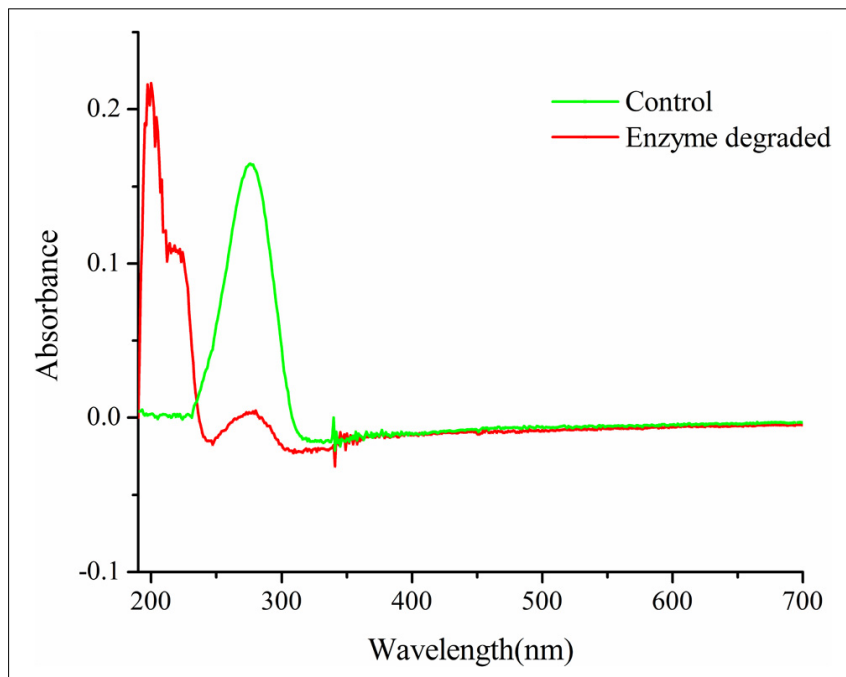

FIGURE 7 | The spectrum of the response result reactions with patulin and PPL.

at low substrate concentration. However, the results showed that the degradation capacity increased with the increasing of initial patulin concentration. A possible explanation for this was that PPL was unsaturated with substrate. It showed that the degradation capacity was going to proportional to the concentration of substrate, according to the characteristic of enzymatic reaction (Berg et al., 2002).

\section{Effect of Contact Time on Patulin Degradation Rate and Degradation Capacity}

Degradation experiments with PPL were conducted at different time and the results were presented in Figure 6. The degradation rate increased with increasing of contact time and reached the maximum value at $48 \mathrm{~h}$. The degradation capacity was following

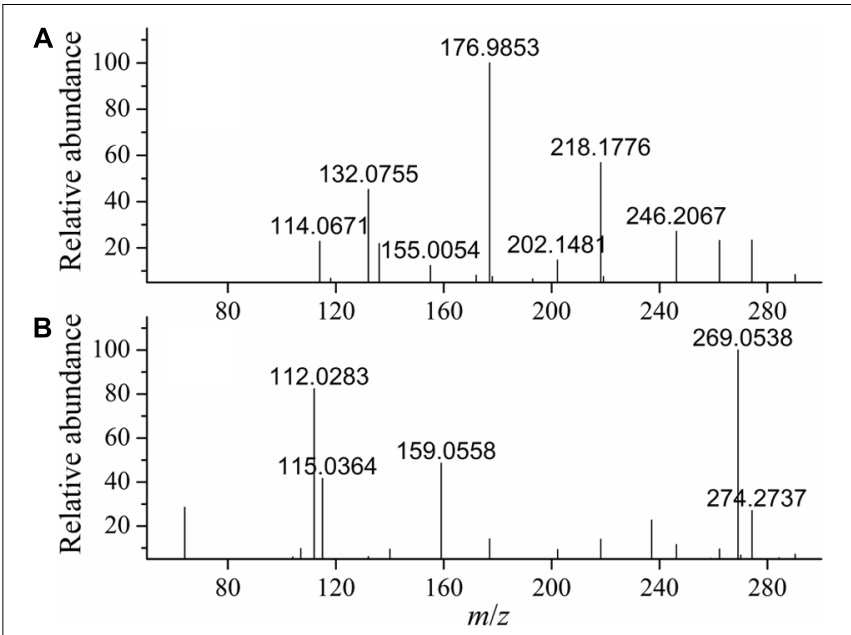

FIGURE 8 | MS/MS before (A) and after (B) PPL degradation.

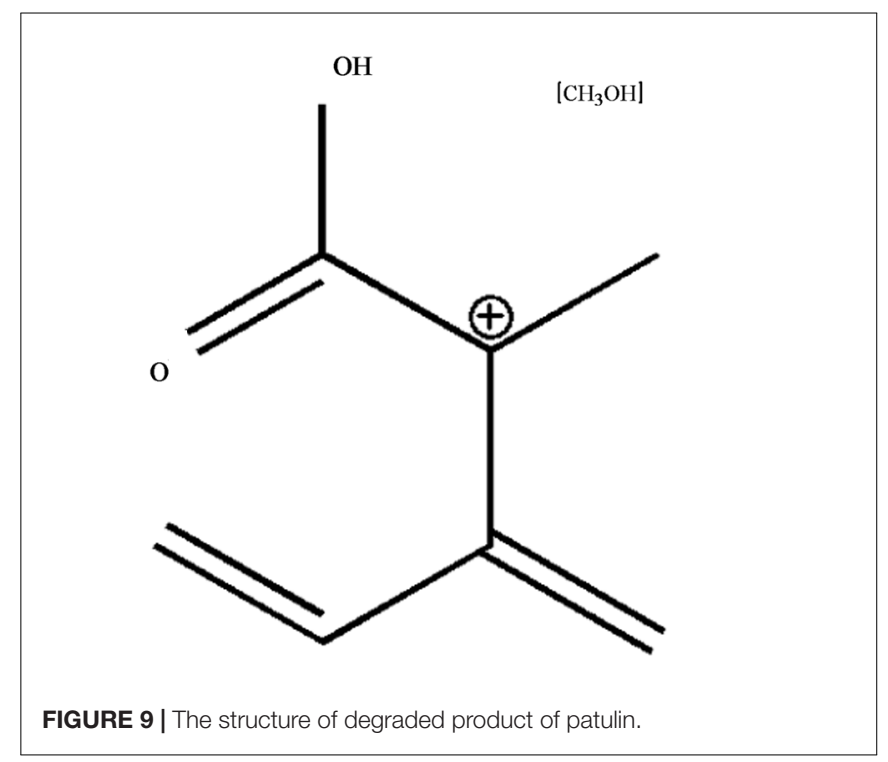

the same trend. The results showed that the rate of degradation increase rapidly with contact time up to $30 \mathrm{~h}$ and then onwards was slow considerably. This was because that the active sites of PPL were more and concentration of patulin was higher during the initial stage of degradation (Kannamba et al., 2010; Peng et al., 2016). Similarly, then declining the active sites of PPL limited the reaction rate to the saturation condition.

\section{Full Wavelength Scanning}

Figure 7 showed the degradation spectrum of patulin at $24 \mathrm{~h}$. The relationship between wavelength of the maximum absorption and structure was also explained (Ibarz et al., 2014). The results showed that the maximum absorption peaks of degradation product shifted to shorter wavelengths. And there was typical absorption of conjugated structures by UV scanning. 


\section{MS Scan of Degradation Products}

MS analyses of patulin before and after PPL degradation were shown in Figure 8. As was shown in Figure 8A, the standard aqueous solution of patulin with $\mathrm{Na}^{+}$adducts $\mathrm{C}_{7} \mathrm{H}_{6} \mathrm{NaO}_{4}$ $(\mathrm{M}+\mathrm{Na})^{+}$calculated: 177.0158, the ESI-MS found: 176.9852 . And patulin was identified at $\mathrm{m} / \mathrm{z}=155.0054$ for protonated cation $[\mathrm{M}+\mathrm{H}]^{+}$. MS of patulin after degradation (Figure $\mathbf{8 B}$ ) showed that the patulin in PPL treated samples was very less than untreated ones. The molecular weight of product might be 159.0558, according with the molecular weight 159.0594 for $\mathrm{C}_{7} \mathrm{H}_{11} \mathrm{O}_{4}{ }^{+}$(Figure 9). It indicated that patulin was reacted with ring opening reaction with PPL. The fragment at $\mathrm{m} / \mathrm{z} 159$ can alternatively undergo successive losses of carbon dioxide (Malysheva et al., 2012). The speculation corresponds to the previous study by UV scanning. It was suggested that patulin was possibly metabolized to degradation product, which was chemically different from patulin.

\section{CONCLUSION}

In this study, PPL has been successfully used to degrade patulin in aqueous solution. It was conjectured that the process of patulin

\section{REFERENCES}

Berg, J. M., Tymoczko, J. L., and Stryer, L. (2002). Biochemistry, 5th Edn. New York, NY: W. H. Freeman and Company.

Castoria, R., Mannina, L., Duránpatrón, R., Maffei, F., Sobolev, A. P., De Felice, D. V., et al. (2011). Conversion of the mycotoxin patulin to the less toxic desoxypatulinic acid by the biocontrol yeast rhodosporidium kratochvilovae strain 1s11. J. Agric. Food Chem. 59, 11571-11578. doi: 10.1021/jf20 $3098 \mathrm{v}$

Castoria, R., Morena, V., Caputo, L., Panfili, G., De Curtis, F., and De Cicco, V. (2005). Effect of the biocontrol yeast Rhodotorula glutinis strain LS11 on patulin accumulation in stored apples. Phytopathology 95, 1271-1278. doi: 10.1094/ PHYTO-95-1271

Dong, X. Y., Jiang, W., Li, C. S., Ma, N., Xu, Y., and Meng, X. H. (2015). Patulin biodegradation by marine yeast Kodameae ohmeri. Food Addit. Contam. Part A 32, 352-360. doi: 10.1080/19440049.2015.1007090

Food Agricultural Organization/World Health Organization [FAO/WHO] (1995). 44th Report of the Joint FAO/WHO Expert Committee on Food Additives. Technical Report. WHO: Geneva.

Giessauf, A., and Gamse, T. (2000). A simple process for increasing the specific activity of porcine pancreatic lipase by supercritical carbon dioxide treatment. J. Mol. Catal. B Enzym. 9, 57-64. doi: 10.1016/S1381-1177(99) 00084-3

Glowacz, G., Bariszlovich, M., Linke, M., Richter, P., Fuchs, C., and Mörsel, J. T. (1996). Stereoselectivity of lipases in supercritical carbon dioxide. Independence of the region and enantioselectivity of porcine pancreas lipase on the water content during the hydrolysis of triolein and its partial glycerides. Chem. Phys. Lipids 79, 101-106. doi: 10.1016/0009-3084(95) 02513-8

Guo, C. X., Yue, T. L., Yuan, Y. H., Wang, Z. L., Guo, Y. D., Wang, L., et al. (2013). Biosorption of patulin from apple juice by caustic treated waste cider yeast biomass. Food Control 32, 99-104. doi: 10.1016/j.foodcont.2012.11.009

Ibarz, R., Garvín, A., Falguera, V., Pagán, J., Garza, S., and Ibarz, A. (2014). Modelling of patulin photo-degradation by a UV multi-wavelength emitting lamp. Food Res. Int. 66, 158-166. doi: 10.1016/j.foodres.2014.09.006

Kabak, B., Dobson, A. D., and Var, I. (2006). Strategies to prevent mycotoxin contamination of food and animal feed: a review. Crit. Rev. Food Sci. Nutr. 46, 593-619. doi: 10.1080/10408390500436185 degradation was enzymatic reaction. Batch studies showed that the degradation percentage of patulin was strongly dependent on reactive conditions such as $\mathrm{pH}$, temperature, initial patulin concentration, and contact time. The complete degradation of patulin occurred at $\mathrm{pH} 7.0,40^{\circ} \mathrm{C}$ for $48 \mathrm{~h}$, the degradation capacity of PPL for patulin is $10.99 \mathrm{mg} / \mathrm{mg}$ PPL. The mechanism of degradation was discussed by using full spectrum scanning and MS analysis. Generally, PPL exhibited good degradation ability and it might have practical application for degradation of patulin in apple juice.

\section{AUTHOR CONTRIBUTIONS}

BL did the experiments and organized the manuscript. XP did the experiments. XM guided the analysis of the catabolite structure.

\section{FUNDING}

This work was financially supported by The National Key R\&D Program of China (2016YFD0400902).

Kannamba, B., Reddy, K. L., and AppaRao, B. V. (2010). Removal of Cu(II) from aqueous solutions using chemically modified chitosan. J. Hazard. Mater. 175, 939-948. doi: 10.1016/j.jhazmat.2009.10.098

Kartal, F., Akkaya, A., and Kilinc, A. (2009). Immobilization of porcine pancreatic lipase on glycidyl methacrylate grafted poly vinyl alcohol. J. Mol. Catal. B Enzym. 57, 55-61. doi: 10.1016/j.molcatb.2008.06.016

Li, J.-k., Wu, R.-n., Hu, Q.-h., and Wang, J.-h. (2007). Solid-phase extraction and HPLC determination of patulin in apple juice concentrate. Food Control 18, 530-534. doi: 10.1016/j.foodcont.2005.12.014

Li, Y., Wang, J. Y., Meng, X. H., and Liu, B. J. (2015). Removal of patulin from aqueous solution using cross-linked chitosan beads. J. Food Saf. 35, 248-256. doi: $10.1111 /$ jfs. 12173

Li, Y. J., Zhou, G. W., Li, C. J., Qin, D. W., Qiao, W. T., and Chu, B. (2009). Adsorption and catalytic activity of Porcine pancreatic lipase on rod-like SBA15 mesoporous material. Colloids Surf. A Physicochem. Eng. Asp. 341, 79-85. doi: 10.1016/j.colsurfa.2009.03.041

MacDonald, S., Long, M., Gilbert, J., and Felgueiras, I. (2000). Liquid chromatographic method for determination of patulin in clear and cloudy apple juices and apple puree: collaborative study. J. AOAC Int. 83, 1387-1394.

Malysheva, S. V., Diana Di Mavungu, J., Boonen, J., De Spiegeleer, B., Goryacheva, I. Y., Vanhaecke, L., et al. (2012). Improved positive electrospray ionization of patulin by adduct formation: usefulness in liquid chromatography-tandem mass spectrometry multi-mycotoxin analysis. J. Chromatogr. A 1270, 334-339. doi: 10.1016/j.chroma.2012.10.060

Martins, J. F., de Carvalho, I. B., de Sampaio, T. C., and Barreiros, S. (1994). Lipasecatalyzed enantioselective esterification of glycidol in supercritical carbon dioxide. Enzyme Microb. Technol. 16, 785-790. doi: 10.1016/0141-0229(94) 90036- 1

Mendes, A. A., Oliveira, P. C., and Castro, H. F. D. (2012). Properties and biotechnological applications of porcine pancreatic lipase. J. Mol. Catal. B Enzym. 78, 119-134. doi: 10.1016/j.molcatb.2012.03.004

Moake, M. M., Padilla-Zakour, O. I., and Worobo, R. W. (2005). Comprehensive review of patulin control methods in foods. Comp. Rev. Food Sci. Food Saf. 4, 8-21. doi: 10.1111/j.1541-4337.2005.tb00068.x

Peng, X. N., Liu, B. J., Chen, W., Li, X. H., Wang, Q. R., Meng, X. H., et al. (2016). Effective biosorption of patulin from apple juice by cross-linked xanthated chitosan resin. Food Control 63, 140-146. doi: 10.1016/j.foodcont.2015. 11.039 
Reddy, K. R., Spadaro, D., Gullino, M. L., and Garibaldi, A. (2011). Potential of two Metschnikowia pulcherrima (yeast) strains for in vitro biodegradation of patulin. J. Food Prot. 74, 154-156. doi: 10.4315/0362-028X.JFP10-331

Yuan, Y., Zhuang, H., Zhang, T. H., and Liu, J. B. (2010). Patulin content in apple products marketed in Northeast China. Food Control 21, 1488-1491. doi: 10.1016/j.foodcont.2010.04.019

Zhang, X. R., Guo, Y. R., Ma, Y., Chai, Y. H., and Li, Y. Y. (2016). Biodegradation of patulin by a Byssochlamys nivea strain. Food Control 64, 142-150. doi: 10.1016/ j.foodcont.2015.12.016

Zheng, X. Y., Baker, H., and Hancock, W. S. (2006). Analysis of the low molecular weight serum peptidome using ultrafiltration and a hybrid ion trap-Fourier transform mass spectrometer. J. Chromatogr. A 1120, 173-184. doi: 10.1016/ j.chroma.2006.01.098

Zhu, J. X., Sun, X. W., Chen, X. L., Wang, S. H., and Wang, D. F. (2016). Chemical cleavage of fucoxanthin from Undaria pinnatifida and formation of apo-fucoxanthinones and apo-fucoxanthinals identified using LC-DAD-APCIMS/MS. Food Chem. 211, 365-373. doi: 10.1016/j.foodchem.2016.05.064

Zhu, R. Y., Feussner, K., Wu, T., Yan, F. J., Karlovsky, P., and Zheng, X. D. (2015). Detoxification of mycotoxin patulin by the yeast Rhodosporidium paludigenum. Food Chem. 179, 1-5. doi: 10.1016/j.foodchem.2015.01.066

Conflict of Interest Statement: The authors declare that the research was conducted in the absence of any commercial or financial relationships that could be construed as a potential conflict of interest.

Copyright (C) 2018 Liu, Peng and Meng. This is an open-access article distributed under the terms of the Creative Commons Attribution License (CC BY). The use, distribution or reproduction in other forums is permitted, provided the original author(s) and the copyright owner are credited and that the original publication in this journal is cited, in accordance with accepted academic practice. No use, distribution or reproduction is permitted which does not comply with these terms. 